\title{
Dietary Restriction and Nicotine can Reduce Anxiety in Female Rats
}

\author{
Rachel F Genn",', Sonia Tucci', Jessica E Edwards' and Sandra E File' \\ 'Psychopharmacology Research Unit, Centre for Neuroscience, GKT School of Biomedical Sciences, King's College London, London, UK
}

\begin{abstract}
Anxiety may play a role in the initiation of smoking and there is evidence to suggest that sex and age may predetermine responses to nicotine. At present, the greatest increase in smoking is in women and it is often accompanied by dieting. The purpose of the present study was to investigate how the impact of dietary restriction might modify the effects of nicotine in female adult and adolescent rats. The effects of nicotine in the elevated plus-maze test of anxiety were compared in free-feeding animals and those subjected to dietary restriction that reduced body weight to $85 \%$ of free-feeding weight. In nondeprived adult females, nicotine $(0.05-0.5 \mathrm{mg} / \mathrm{kg}$, s.c.) reduced the percentage of time spent on the open arms, indicating anxiogenic effects. However, the effects of nicotine were dramatically changed in food-restricted adult females and $0.05 \mathrm{mg} / \mathrm{kg}$ had a striking anxiolytic effect. No significant effects of nicotine were found in the adolescent female rats, suggesting a role of circulating sex hormones in modulating nicotine's effects on anxiety. However, in the adolescent females, dietary restriction significantly increased the percentages of time spent and entries onto the open arms, without changing closed arm entries, indicating an anxiolytic effect. These results raise the important possibility that, in prepubertal girls, dietary restriction may have anxiolytic effects and this might contribute to the onset of anorexia. Circulating female hormones reduce this effect, but in adult females the combination of dietary restriction and nicotine may have important anxiolytic effects that impact on the initiation of regular smoking.

Neuropsychopharmacology (2003) 28, 1257-1263, advance online publication, 9 April 2003; doi: I 0. I038/sj.npp. I 300 I 68
\end{abstract}

Keywords: nicotine; females; adolescence; anxiety; dietary restriction; anorexia

\section{INTRODUCTION}

Young women are the most likely group of people to start smoking and to diet and, in some cases, these two activities are linked. Smoking in order to lose weight is often reported by women (Grunberg et al, 1986), and Pomerleau et al (1993) have identified the female 'weight-control smoker' as a group in which weight loss is a prime motive for smoking. Nicotine is well established as an appetite suppressant and, in general, smokers weigh less than nonsmokers (Comstock and Stone, 1972; Perkins et al, 1992; Crisp et al, 1999). Female sex hormones may play an important role in this effect, and Crisp et al (1999) found that smoking resulted in greater weight loss in schoolgirls only after the onset of puberty. The results from animal experiments also identify the prepubertal female as responding differently to the appetite suppressant effects of nicotine. The adolescent rat

\footnotetext{
*Correspondence: Dr RF Genn, Psychopharmacology Research Unit, Centre for Neuroscience, GKT School of Biomedical Sciences, King's College London, Hodgkin Building, Guy's Campus, London SEI IUL, UK, Tel: +20 7847 6668, Fax: +20 7848 6660,

E-mail: rachel.f.genn@kcl.ac.uk

Received 16 August 2002; revised 31 October 2002; accepted 02 January 2003

Online publication: 20 January 2003 at http://www.acnp.org/citations/ Npp0I2003463
}

(days 29-42) provides a useful model in which there is sexual differentiation of the brain, but an absence of circulating gonadal hormones (Spear and Brake, 1983). The body weight and food intake of female adolescent rats did not change in response to a $12 \mathrm{mg} / \mathrm{kg} /$ day nicotine infusion, whereas there were significant changes in male adolescents and male and female adults (Faraday et al, 2001).

There is evidence for other sex differences in the motivation to smoke. For example, men often nominate the rewarding effects of cigarettes as their reason for smoking, whereas women cite anxiety-reducing effects (Perkins et al, 1999; Crisp et al, 1999). Furthermore, women are more likely than men to smoke in order to relieve negative withdrawal symptoms (Stanton, 1995), and women experience more withdrawal symptoms than men when the number of cigarettes smoked is matched (Kandel and Chen, 2000). In nonsmokers, nicotine had calming effects in young women, but increased anxiety and aggression in young men (File et al, 2001). However, these sex differences were not found in regular smokers (File et al, 2002), which suggests that sex differences in nicotine's effects on anxiety may be of prime importance in the initiation of smoking. The results from animal experiments also provide evidence for sex differences in response to nicotine's effects on anxiety. In the open field, nicotine had a greater anxiolytic effect in adult female rats than in adult male rats (Faraday et al, 2001). 
In addition, there may be important age differences in response to nicotine. In females, the subjective benefits of smoking are higher in adolescents than adults (Crisp et al, 1999). This is particularly important, since early onset of cigarette use is a robust predictor of dependence in later life (Taioli and Wynder, 1991; Breslau et al, 1993) and of failure in smoking cessation (Nides et al, 1995). Adolescents smoke significantly fewer cigarettes than adults, yet experience higher rates of dependence at the same levels of use (Kandel and Chen, 2000). In line with the human findings, much of the data gathered from animals also reflect a peculiar vulnerability to nicotine in adolescence (Laviola et al, 1999; Adriani et al, 2002). In mice, it seems that early adolescence in particular (during the period just preceding puberty) is the developmental phase responsible for the pattern of behaviors constituting sensitivity to nicotine's effects (Adriani et al, 2002). During this phase, mice orally administer a significantly greater volume of nicotine solution compared to middle or late adolescence. In the social interaction test of anxiety, female adolescent rats showed an anxiolytic response to nicotine at a five-fold lower dose than male adolescent rats (Cheeta et al, 2001a).

While the effects of nicotine have not, so far, been examined in conjunction with dietary restriction, there is evidence that food deprivation incurs physiological effects mediated by the hypothalamic-pituitary axis (HPA). In male rats, 2 days of total deprivation did not change corticosterone concentrations, but they were increased after 10 days without food (Yoshihara et al, 1996), and after 8 days of food restriction to ensure a body weight that was maintained at $80 \%$ of that on day 1 they were also increased (Heiderstadt et al, 2000). However, the same authors did not find any difference in serum corticosterone levels between controls and rats maintained at $80 \%$ of an ad libitum fed control rat over 21 days. Even very brief $(24 \mathrm{~h})$ food deprivation can increase plasma corticosterone concentrations in ovariectomized female rats (Chang et al, 2002), suggesting that food deprivation is stressful in this group, at least as measured by activation of the HPA. However, what remains equivocal is the degree of severity of deprivation required to induce changes in HPA and processes dependent on the equilibrium of this axis such as menstruation (Tropp and Markus, 2001).

There is also evidence that circulating gonadal hormones can influence anxiety. Anxiety levels of female rats are lower during proestrous than during diestrous, and levels of estradiol modulate this response (Klein Marcondes et al, 2001). This is evidenced by increases in percentage time spent on open arms by the proestrous animals than diestrous. There were no significant differences in the percentage of entries into the open arms or in the number of entries into the closed arms among the phases of the estrous cycle. Further, Frye et al (2000) have evidence to suggest that proestrous (when estradiol and progesterone peak) promotes increases in anxiolytic-like behavior in plus-maze coincident with elevated circulating progestin concentrations. Since the estrous cycle seems to modulate performance on anxiety tasks, it is interesting to note that behaviors dependent on the cycle (such as lordosis) are, in turn, sensitive to food availablity. Jones et al (2002) showed that in hamsters food-deprived for $48 \mathrm{~h}$, estrous behavior is suppressed. This suppression can be delayed by enriching the animals' diet with high-calorie macronutrients (Tropp and Markus, 2001). This is a finding that is mirrored in the clinical literature on anorexia nervosa in that one of the most salient features of this disorder is amenorrhea (the lack of three consecutive menstrual cycles; DSM-IV, 1994). To date, there is no effective therapy available for anorexia, but the fact that many periadolescent anorexics 'grow out of the disorder in adulthood (Herpertz-Dahlmann et al, 1996) hints towards a potential role of post-menarchal hormones in recovery from the disorder.

The purpose of the present experiment was to examine the impact of dietary restriction in adolescent and young adult female rats on the effects of nicotine in the elevated plus-maze. This test of anxiety has been widely validated (Pellow et al, 1985; Pellow and File, 1986) and has been used to test both male and female rats (Johnston and File, 1991; Steenbergen et al, 1991; Imhof et al, 1993). Brioni et al (1994) reported an anxiolytic effect of nicotine $(0.3 \mathrm{mg} / \mathrm{kg})$ in this test. Others, using adult male hooded Lister rats, observed no effects of low doses of nicotine while higher doses $(0.1-1.0 \mathrm{mg} / \mathrm{kg}$ ) had anxiogenic effects (Ouagazzal et $a l, 1999$; Cheeta et al, 2001b). To date, the effects of nicotine on female rats in the plus-maze have not been examined but bimodal effects of nicotine in animal tests of anxiety are now well recognized. Nicotine has been found to have anxiolytic effects in the potentiated startle test (Vale and Green, 1996) and at low doses in the social interaction test (File et al, 1998). In the black-white crossing test in mice, nicotine has anxiogenic effects (Costall et al, 1989), as it does at high doses in the social interaction test (File et al, 1998). For a review of these complex effects of nicotine on anxiety in both animals and humans, see Picciotto et al (2002).

\section{MATERIALS AND METHODS}

\section{Animals and Dietary Restriction}

Female hooded Lister rats (Harlan Olac, Bicester, UK) were housed singly in cages $45 \times 28 \times 20 \mathrm{~cm}^{3}$ high. All cages were in racks that allowed rats to see, hear, and smell other rats. The room in which the animals were housed was lit with dim light and maintained at $22^{\circ} \mathrm{C}$. Lights were on from 0700-1900 $\mathrm{h}$. The adolescent rats were aged 28 days at the start of the experiment and were tested at day 35 . The adult rats were approximately 70 days.

At the start of the experiment, half of each group was randomly allocated to the dietary restriction condition. For both groups, water was available at all times. Dietary restriction occurred for 7 days. Each day all animals were weighed. Based upon a change in the animal's weight from the previous day, an individually calculated amount of food was given to the food-restricted animals once per day, in order to maintain their weight at $85 \%$ of their free-feeding cohort. On average, about $12 \mathrm{~g}$ per day was given to the adult females and about $10 \mathrm{~g}$ per day to the adolescent females. Feeding took place between 1400 and $1600 \mathrm{~h}$. At the time of testing (on day 8) the adult female rats weighed $208 \mathrm{~g}$ (deprived) and $250 \mathrm{~g}$ (nondeprived) and the female adolescent rats (day 28) weighed $93 \mathrm{~g}$ (deprived) and $110 \mathrm{~g}$ (nondeprived). The experimental procedures carried out in this study were in compliance with the UK Animals 
(Scientific Procedures) Act 1986 (Home Office Project Licence Number 70/5436).

\section{Apparatus}

The elevated plus-maze was made of wood and consisted of two opposite open arms $50 \times 10 \mathrm{~cm}^{2}$, and two opposite equal sized arms enclosed by $40 \mathrm{~cm}$ high walls. The arms were connected by a central $10 \times 10 \mathrm{~cm}^{2}$, and thus the maze formed a 'plus' shape. The maze was elevated $50 \mathrm{~cm}$ from the floor and lit by dim light. A closed-circuit TV camera was mounted vertically over the maze, and the behavior was scored from a monitor in an adjacent room. All scores were entered directly into an IBM computer. The percentage of time spent and the percentage of entries onto the open arms of the maze provide the measures of anxiety, and increases in these measures indicate an anxiolytic effect whereas decreases indicate an anxiogenic effect (Pellow et al, 1985; Pellow and File, 1986). The number of closed arm entries provides the best measure of locomotor activity in this test (File, 1992). An arm entry was defined as all four paws entering the arm and an arm exit was defined as two paws leaving the arm.

\section{Drug}

(-)-Nicotine hydrogen tartrate (Sigma, Poole, UK) was dissolved in distilled water, and the doses of nicotine were calculated as the base. All drug injections were given subcutaneously (s.c.) in a volume of $1 \mathrm{ml} / \mathrm{kg}$ body weight. Control animals received equal volume injections of distilled water. The animals were tested $30 \mathrm{~min}$ after injection.

\section{Procedure}

Within each dietary condition, female adult rats were randomly allocated among the following drug groups, with $n=8$ /group: vehicle, (-)-nicotine $(0.05,0.25$, or $0.5 \mathrm{mg} / \mathrm{kg})$. Within each dietary condition, female adolescent rats were randomly allocated among the following drug groups, with $n=12$ /group: vehicle, $(-)$-nicotine $(0.05,0.1,0.25$, or $0.5 \mathrm{mg} / \mathrm{kg}$ ). On the test day, $30 \mathrm{~min}$ after injection each rat was placed in the central square of the plus-maze facing the closed arm, and its behavior was scored for $5 \mathrm{~min}$ by an observer blind to the drug treatment and dietary condition. The number of entries onto the open and closed arms, and the time spent on the open arms, closed arms, and central square were scored. The test arena was wiped with a damp cloth after each trial. The rats were tested between 0900 and $1300 \mathrm{~h}$, in an order randomized for drug treatment and dietary condition.

\section{Statistics}

The data were analyzed by two-way analyses of variance (Factor 1, drug treatment; Factor 2, dietary condition). Comparisons between individual groups were then made with Fisher's LSD test, and it is the significances of these comparisons that are shown in Figure 1 and Table 1.

\section{RESULTS}

\section{Adult Females}

It can be seen from Figure 1 that, in the adult females, dietary restriction dramatically changed the effects of nicotine on the percentage of time spent on the open arms (dietary state $\times$ nicotine interaction, $\mathrm{F}(3,56)=10.14$, $p<0.01)$. This was particularly marked for the lowest dose $(0.05 \mathrm{mg} / \mathrm{kg})$, which significantly reduced the percentage time spent on the open arms in the free-feeding group, but significantly increased it in the food-restricted animals. Thus, in food-restricted adult females, there was a highly significant anxiolytic effect of the lowest dose of nicotine, while the same dose had an anxiogenic effect in free-feeding adult females. A similar pattern can be seen in the percentage of open arm entries, but overall the interaction did not reach significance (nicotine: $\mathrm{F}(3,56)=0.9$, NS), although there was a main effect of dietary restriction to increase the percentage of open arm entries (dietary state: $\mathrm{F}(1,56)=4.9, p<0.05)$. Neither factor, nor the interaction between the two factors, had an effect on the number of closed arm entries (dietary state: $\mathrm{F}(1,56)=1.05$, NS; drug:

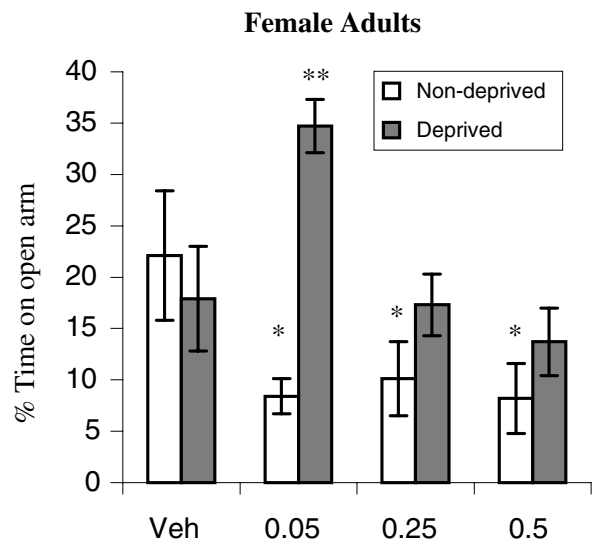

Figure I Mean ( \pm SEM) percentage of time spent on the open arms by adult female rats tested in the elevated plus-maze after s.c. injection of vehicle or nicotine $(0.05,0.25$, or $0.5 \mathrm{mg} / \mathrm{kg}), N=8$ per dose group. Unfilled bars represent nondeprived animals, and filled bars represent deprived animals; ${ }^{*} p<0.05$, ${ }^{*} p<0.0$ l compared with vehicle control from the same dietary condition, LSD after ANOVA.

Table I Mean ( \pm SEM) Percentage of Open Arm Entries and Number of Closed Arm Entries in the Plus-Maze on Trial I by Female Adult Rats after s.c. Injection of Vehicle or Nicotine ( 0.05 , 0.25 , and $0.5 \mathrm{mg} / \mathrm{kg}$ )

\begin{tabular}{lccccc}
\hline & \multicolumn{2}{c}{$\begin{array}{c}\text { Percentage of } \\
\text { open arm entries }\end{array}$} & & \multicolumn{2}{c}{$\begin{array}{c}\text { Number closed } \\
\text { arm entries }\end{array}$} \\
\cline { 2 - 3 } \cline { 5 - 6 } $\begin{array}{l}\text { Nicotine } \\
(\mathbf{m g} / \mathbf{k g})\end{array}$ & Nondeprived & Deprived & & Nondeprived & Deprived \\
\hline 0 & $24.4 \pm 5.7$ & $26.7 \pm 5.1$ & & $9.6 \pm 0.6$ & $9.1 \pm 0.5$ \\
0.05 & $19.8 \pm 3.1$ & $33.9 \pm 3.6 *$ & & $9.0 \pm 0.9$ & $9.1 \pm 0.7$ \\
0.25 & $25.7 \pm 5.2$ & $27.4 \pm 5.2$ & & $8.0 \pm 0.7$ & $9.6 \pm 0.7$ \\
0.5 & $16.4 \pm 4.5$ & $25.7 \pm 3.9$ & & $7.9 \pm 1.0$ & $8.8 \pm 0.5$ \\
\hline$* 2 p<0.05$ compared with the nondeprived group; $N=8$ per dose group.
\end{tabular}


Table 2 Mean ( \pm SEM) Percentage of Open Arm Entries, Percentage Time on Open Arm and Number of Closed Arm Entries in the Plus-Maze by Female Adolescent Rats Received s.c. Injection of Vehicle or Nicotine $(0.05,0.1,0.25$, and $0.5 \mathrm{mg} / \mathrm{kg})$

\begin{tabular}{|c|c|c|c|c|c|c|}
\hline \multirow{2}{*}{$\begin{array}{c}\text { Nicotine } \\
\text { (mg/kg) }\end{array}$} & \multicolumn{2}{|c|}{ Percentage of time open arm } & \multicolumn{2}{|c|}{ Percentage of open arm entries } & \multicolumn{2}{|c|}{ Closed arm entries } \\
\hline & Nondeprived & Deprived $^{* * *}$ & Nondeprived & Deprived $* * *$ & Nondeprived & Deprived \\
\hline 0 & $24.4 \pm 3.2$ & $30.2 \pm 4.5$ & $32.3 \pm 2.6$ & $40.7 \pm 2.7$ & $11.6 \pm 0.6$ & $9.5 \pm 0.5$ \\
\hline 0.05 & $23.3 \pm 2.8$ & $29.8 \pm 4.6$ & $33.1 \pm 1.5$ & $35.1 \pm 2.1$ & $10.75 \pm 0.5$ & $10.5 \pm 0.5$ \\
\hline 0.1 & $16.2 \pm 3.0$ & $34.7 \pm 4.2$ & $27.2 \pm 2.3$ & $38.9 \pm 2.5$ & $11.6 \pm 0.8$ & $10.6 \pm 0.6$ \\
\hline 0.25 & $18.6 \pm 3.7$ & $29.1 \pm 3.6$ & $27.1 \pm 3.5$ & $34.5 \pm 3.1$ & $1 \mid .4 \pm 0.7$ & $12.8 \pm 0.7$ \\
\hline 0.5 & $19.3 \pm 3.7$ & $24.2 \pm 4.4$ & $25.6 \pm 2.6$ & $32.4 \pm 4.1$ & $11.5 \pm 0.7$ & $12.2 \pm 1.1$ \\
\hline
\end{tabular}

**** $p<0.001$, significant effects of dietary state (see Figure 2); $N=12$ per dose group.
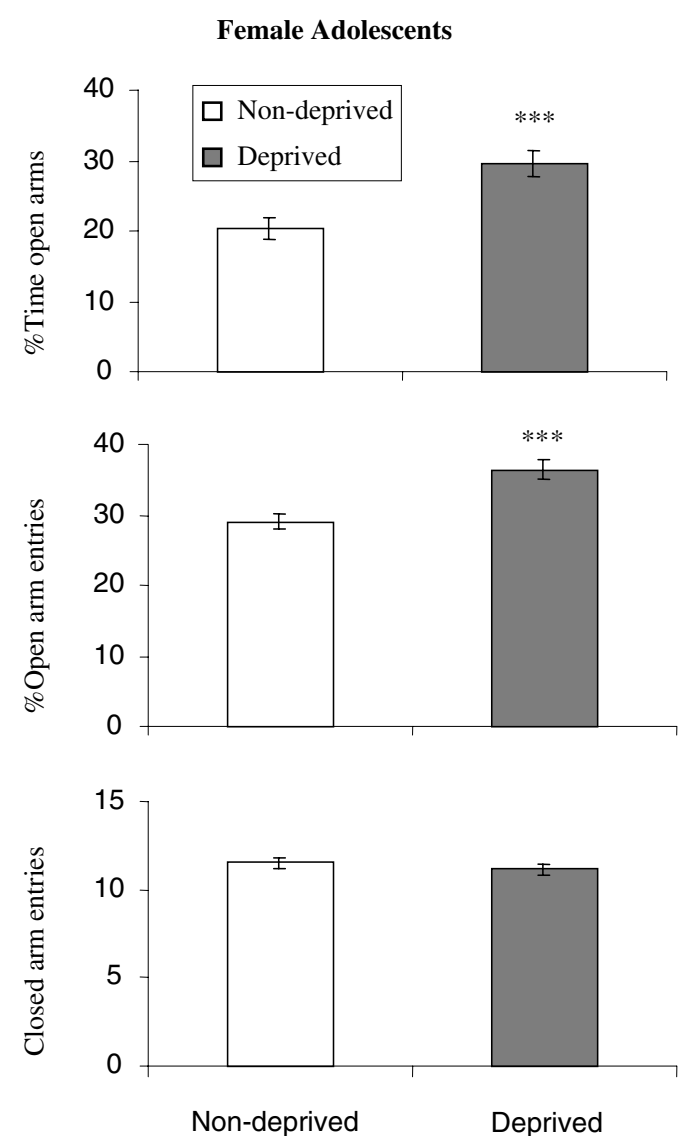

Figure 2 Mean ( \pm SEM) percentage of time spent on the open arms (top panel), percentage of open arm entries (middle panel), and number of closed arm entries (bottom panel) in the elevated plus-maze by freefeeding (nondeprived, unfilled bars) and food-restricted (deprived, filled bars) adolescent female rats ( $N=60$ per deprivation group) (*** $p<0.00$ I compared with nondeprived ANOVA).

$\mathrm{F}(3,56)=0.75$; dietary state $\times$ nicotine: $\mathrm{F}(3,56)=0.8, \mathrm{NS})$; see Table 1 .

\section{Adolescent Females}

Effects of nicotine. In contrast with the adult females, in adolescent females, nicotine was without significant effect (nicotine: $F(4,110)=0.7,2.1$, and 2.0, for percent time, and percent entries onto open arms, and number of closed arm entries, respectively, NS in all cases) and dietary restriction did not modify nicotine's effects (dietary state $\times$ nicotine interaction, $\mathrm{F}(4,110)=1.1,0.8$, and 1.9 , for percent time, and percent entries onto open arms, and number of closed arm entries, respectively, NS in all cases); see Table 2.

\section{Effects of Dietary Restriction}

The adolescent females did, however, show striking effects of dietary restriction on the measures of anxiety; see Figure 2. Dietary restriction had significant anxiolytic effects, shown by increases in the percentage of time spent on the open arms $(\mathrm{F}(1,110)=14.3, p<0.001)$ and in the percentage of open arm entries (dietary state: $\mathrm{F}(1,110)=17.0$, $p<0.0001)$. Dietary restriction did not change the number of closed arm entries (dietary state: $\mathrm{F}(1,110)=0.3$, NS).

\section{DISCUSSION}

The present experiment is the first to report the effects of nicotine on the responses of female rats in the elevated plusmaze. In the free-feeding adult female, nicotine reduced the percentage of time spent on the open arms, without changing the number of closed arm entries, thus indicating a specific anxiogenic effect, rather than a nonspecific reduction in responding. The decrease in percentage of time spent on the open arms reached significance at $0.05 \mathrm{mg} / \mathrm{kg}$, a lower dose than that previously found to change this measure in male rats tested under similar experimental conditions (Ouagazzal et al, 1999; Cheeta et al, 2001b). Cheeta et al (2001b) found that nicotine also reduced the percentage of open arm entries, but Ouagazzal et al (1999) found this measure to be decreased only by $1 \mathrm{mg} / \mathrm{kg}$, a dose higher than the range investigated in this study. In neither the male nor the female rats has there been clear evidence that the anxiogenic effects of nicotine were dose-related. Rather it seems that a threshold effect has to be reached in order to trigger an anxiogenic response. We do not really know the reason for this, but it may relate to the indirect effects of nicotine, perhaps by acting at presynaptic receptors to enhance neurotransmitter release. The neurochemical mechanisms have not been explored in the plus-maze, but in the social interaction test the evidence suggests that nicotine exerts its anxiogenic effect by increasing 5-HT release (see File et al, 2000 for a review). In the hippocampus, nicotine increases 5-HT release and has an anxiogenic effect only at a high dose (Kenny et al, 2000a, b).

The evidence from both the present study and from previous studies in adult male rats is that the effects of 
nicotine are more marked on the percentage of time than on the percentage of entries on the open arms. This is similar to the effects of the estral cycle in the plus-maze, which were significant only for percentage time. One reason for this is that the two measures are not equally sensitive and, for this reason, many studies only report percentage of time. A factor analysis of the measures in the plus-maze for female hooded Lister rats (as used in this study) showed that percentage time loaded more highly on the anxiety factor than did percentage entries (Fernandes et al, 1999). Furthermore, in rats selectively bred for different levels of anxiety in the plus-maze, discriminant analysis showed that for both male and female rats percentage time was the most important variable for distinguishing between the lines, with percentage entries not reaching significance (Henniger et al, 2000).

In the adult females, dietary restriction dramatically changed the direction of nicotine's effects on the percentage of time spent on the open arms, without changing nicotine's effects on closed arm entries, indicating specific effects on anxiety. Thus, whereas in the free-feeding situation nicotine at all doses had anxiogenic effects, in contrast, in the condition of dietary restriction the lowest dose of nicotine $(0.05 \mathrm{mg} / \mathrm{kg})$ had a marked anxiolytic effect. We do not know whether anxiolytic effects would also have been seen at even lower doses of nicotine, or whether anxiogenic effects would have been found after even higher doses than those we tested. In the adult female rats, it can be seen from the scores of the vehicle-treated rats that dietary restriction did not change the percentage of time spent on the open arms. It is therefore unlikely that the changed pattern of nicotine's effects on this measure could have been secondary to its effects on appetite.

The directional shift in nicotine's effects on anxiety caused by dietary restriction was not seen in the adolescent rats, suggesting that circulating female gonadal hormones were necessary for the expression of this shift. Circulating gonadal hormones have previously been found to modify the anxiolytic effects of chronically administered desipramine (Fernandez-Guasti et al, 1999). The results of reduced anxiolytic effects in female adolescent rats in the plus-maze contrast with the enhanced responses previously found in the social interaction test (Cheeta et al, 2001a). There is evidence that different neurochemical pathways are important in behavior in the plus-maze and social interaction tests (Cheeta et al, 2000; File et al, 1996; Gonzalez et al, 1998, 1996). Thus, the pattern of results seen with nicotine suggests that the adolescent period may be one in which there are regional differences in brain 5-HT development. $\mathrm{Xu}$ et al (2001) found that nicotine administration to adolescent rats resulted in suppression of presynaptic 5-HT activity. This would normally be followed by a compensatory upregulation of postsynaptic receptors. However, they found that postsynaptic 5-HT receptor density and their ability to modulate cell signalling was actually suppressed by nicotine administration in adolescents (Xu et al, 2002). The changes in postsynaptic 5-HT receptors were both brain region and sex dependent, with females showing the main effects in $5-\mathrm{HT}_{2}$ receptors. Xu et al (2002) hypothesized that the dysregulatory effects seen in the 5-HT system as a result of nicotine administration might provide the biological basis for the emergence of depression during attempts at smoking cessation. While we cannot yet link our findings directly with the 5-HT system, this would seem to be one of the main candidates for mediating our changed responses to nicotine.

Our results may also have clinical implications for the onset of regular smoking in young women. They raise the important possibility that the coincidence of dieting and smoking may change the emotional impact of nicotine, enhancing its anxiolytic effects and reducing its anxiogenic effects. This could further amplify sex differences in the anxiolytic $v s$ anxiogenic effects of nicotine (Cheeta et al, 2001a; File et al, 2001), and thus contribute to the difference in motivation underlying smoking onset. On withdrawal from nicotine and smoking, there is a rebound hyperphagia and weight gain (Blitzer et al, 1977; Grunberg, 1982; Carney and Goldberg, 1984), and this may be exacerbated if nicotine withdrawal is also accompanied by the end of a previous period of dieting. It would be of great interest to determine whether termination of dietary restriction would also exacerbate the anxiogenic response that is detected in the plus-maze on withdrawal from chronic administration of nicotine (Irvine et al, 2001).

In the adolescent female rats, dietary restriction significantly increased the percentages of open arm entries and time spent on the open arms, without changing the number of closed arm entries. This suggests, perhaps surprisingly, that in this group, dietary restriction had some anxiolytic effect. Thus we have replicated in a larger sample of animals the previously reported anxiolytic responses in the plusmaze following dietary restriction (Genn et al, 2003). However, no significant effects of food deprivation were found in the social interaction test (Genn et al, 2003). Factor analysis has shown that measures from the two tests load on independent factors of anxiety (File, 1992), and thus it may be that dieting can differentially affect different anxiety states.

There is clinical evidence to suggest that anxiety disorders are risk factors for subsequent eating disorders, with $83 \%$ of subjects with anorexia nervosa having at least one lifetime diagnosis of an anxiety disorder (Bulik et al, 1997; Godart et al, 2000), particularly panic disorder (Brawman-Mintzer et $a l, 1995)$. Our results raise the intriguing speculation that dieting may serve to reduce anxiety and this positive motivational effect may serve as one factor reinforcing anorexia, particularly before the onset of puberty. Our results suggest that circulating female hormones in the adult female inhibit the anxiolytic effects of food restriction seen in the adolescents. Thus the onset of puberty, and its incumbent neurochemical changes, may serve to reduce the positive emotional impact of dieting. This hypothesis is congruous with the finding that most periadolescent anorexics 'grow out of the disorder in adulthood (Herpertz-Dahlmann et al, 1996).

\section{ACKNOWLEDGMENTS}

This study was supported by CONICIT-ULA, Venezuela.

\section{REFERENCES}

Adriani W, Macri S, Pacifici R, Laviola G (2002). Peculiar vulnerability to nicotine oral self-administration in mice during early adolescence. Neuropsychopharmacology 27: 212-224. 
Blitzer PH, Rimm AA, Giefer EE (1977). The effect of cessation of smoking on body weight in 57,032 women: cross-sectional and longitudinal analyses. J Chronic Dis 30: 415-429.

Brawman-Mintzer O, Lydiard RB, Phillips KA, Morton A, Czepowicz V, Emmanuel N et al (1995). Body dysmorphic disorder in patients with anxiety disorders and major depression: a comorbidity study. Am J Psychiatry 152: 1665-1667.

Breslau N, Fenn N, Peterson EL (1993). Early smoking initiation and nicotine dependence in a cohort of young adults. Drug Alcohol Depend 33: 129-137.

Brioni JD, O’Neill AB, Kim DJ, Buckley MJ, Decker MW, Arneric SP (1994). Anxiolytic-like effects of the novel cholinergic channel activator ABT-418. J Pharmacol Exp Ther 271: 353-361.

Bulik CM, Sullivan PF, Fear JL, Joyce PR (1997). Eating disorders and antecedent anxiety disorders: a controlled study. Acta Psychiatr Scand 96: 101-107.

Carney RM, Goldberg AP (1984). Weight gain after cessation of cigarette smoking. A possible role for adipose-tissue lipoprotein lipase. $N$ Engl J Med 310: 614-616.

Chang LL, Kau MM, Wun WS, Ho LT, Wang PS (2002). Effects of fasting on corticosterone production by zona fasciculatareticularis cells in ovariectomized rats. J Invest Med 50: 86-94.

Cheeta S, Irvine E, File S (2001b). Social isolation modifies nicotine's effects in animal tests of anxiety. Br J Pharmacol 132: 1389-1395.

Cheeta S, Irvine EE, Tucci S, Sandhu J, File SE (2001a). In adolescence, female rats are more sensitive to the anxiolytic effect of nicotine than are male rats. Neuropsychopharmacology 25: 601-607.

Cheeta S, Kenny P, File S (2000). Hippocampal and septal injections of nicotine and 8-OH-DPAT distinguish among different animal tests of anxiety. Prog Neuropsychopharmacol Biol Psychiatry 24: 1053-1067.

Comstock GW, Stone RW (1972). Changes in body weight and subcutaneous fatness related to smoking habits. Arch Environ Health 24: 271-276.

Costall B, Kelly ME, Naylor RJ, Onaivi ES Wong EH, Smith WL et al (1989). The actions of nicotine and cocaine in a mouse model of anxiety. Pharmacol Biochem Behav 33: 197-203.

Crisp A, Sedgwick P, Halek C, Joughin N, Humphrey H (1999). Why may teenage girls persist in smoking. J Adolesc 22: 657-672.

DSM-IV (1994). Diagnostic and Statistical Manual of Mental Disorders. American Psychiatric Association: Washington, DC.

Faraday MM, Elliott BM, Grunberg NE (2001). Adult vs adolescent rats differ in biobehavioral responses to chronic nicotine administration. Pharmacol Biochem Behav 70: 475-489.

Fernandes C, Gonzalez MI, Wilson CA, File SE (1999). Factor analysis shows that female rat behaviour is characterized primarily by activity, male rats are driven by sex and anxiety. Pharmacol Biochem Behav 64: 731-738.

Fernandes-Guasti A, Martinez-Mota L, Estrada-Camarena E, Contreras CM, Lopez-Rubalcava C (1999). Chronic treatment with desipramine induces an estrous cycle-dependent anxiolyticlike action in the burying behavior, but not in the elevated plusmaze test. Pharmacol Biochem Behav 63: 13-20.

File SE (1992). Behavioural detection of anxiolytic action. In: Elliott JM, Heal DJ, Marsden CA (eds). Experimental Approaches to Anxiety and Depression. Wiley: London. pp 25-44.

File SE, Dinnis AK, Heard JE, Irvine EE (2002). Mood differences between male and female light smokers and nonsmokers. Pharmacol Biochem Behav 72: 681-689.

File SE, Fluck E, Leahy A (2001). Nicotine has calming effects on stress induced mood changes in females but enhances aggression in males. Int J Neuropsychopharmacol 4: 371-376.

File SE, Gonzalez LE, Andrews N (1996). Comparative study of preand postsynaptic 5-HT1A receptor modulation of anxiety in two ethological animal tests. J Neurosci 16: 4810-4815.
File SE, Kenny PS, Ouaghzzal AM (1998). Bimodal modulation by nicotine of anxiety in the social interaction test: role of the dorsal hippocampus. Behav Neurosci 112: 1423-1429.

File SE, Kenny PJ, Cheeta S (2000). The role of the dorsal hippocampal serotonergic and cholinergic systems in the modulation of anxiety. Pharmacol Biochem Behav 66: 65-72.

Frye CA, Petralia SM, Rhodes ME (2000). Estrous cycle and sex differences in performance on anxiety tasks coincide with increases in hippocampal progesterone and 3alpha, 5alphaTHP. Pharmacol Biochem Behav 67: 587-596.

Genn RF, Tucci SA, Thomas A, Edwards JE, File SE (2003). Age associated sex differences in response to food deprivation in two animal tests of anxiety. Neurosci Biobehav Rev, in press.

Godart NT, Flament MF, Lecrubier Y, Jeammet P (2000). Anxiety disorders in anorexia nervosa and bulimia nervosa: comorbidity and chronology of appearance. Eur Psychiatry 15: 38-45.

Gonzalez LE, Andrews N, File SE (1996). 5-HT1A and benzodiazepine receptors in the basolateral amygdala modulate anxiety in the social interaction test, but not in the elevated plus-maze. Brain Res 732: 145-153.

Gonzalez LE, Ouagazzal AM, File SE (1998). Stimulation of benzodiazepine receptors in the dorsal hippocampus and median raphe reveals differential GABAergic control in two animal tests of anxiety. Eur J Neurosci 10: 3673-3680.

Grunberg NE (1982). The effects of nicotine and cigarette smoking on food consumption and taste preferences. Addict Behav 7: 317-331.

Grunberg NE, Bowen DJ, Winders SE (1986). Effects of nicotine on body weight and food consumption in female rats. Psychopharmacology (Berlin) 90: 101-105.

Heiderstadt KM, McLaughlin RM, Wright DC, Walker SE, GomezSanchez CE (2000). The effect of chronic food and water restriction on open-field behaviour and serum corticosterone levels in rats. Lab Anim 34: 20-28.

Henniger MS, Ohl F, Holter SM, Weissenbacher P, Toschi N, Lorscher $\mathrm{P}$ et al (2000). Unconditioned anxiety and social behaviour in two rat lines selectively bred for high and low anxiety-related behaviour. Behav Brain Res 111: 153-163.

Herpertz-Dahlmann BM, Wewetzer C, Schulz E, Remschmidt H (1996). Course and outcome in adolescent anorexia nervosa. Int J Eat Disord 19: 335-345.

Imhof JT, Coelho ZM, Schmitt ML, Morato GS, Carobrez AP (1993). Influence of gender and age on performance of rats in the elevated plus maze apparatus. Behav Brain Res 56: 177-180.

Irvine EE, Cheeta S, File SE (2001). Tolerance to nicotine's effects in the elevated plus-maze and increased anxiety during withdrawal. Pharmacol Biochem Behav 68: 319-325.

Johnston AL, File SE (1991). Sex differences in animal tests of anxiety. Physiol Behav 49: 245-250.

Jones JE, Pick RR, Wade GN (2002). Food deprivation inhibits estrous behavior in hormone-treated syrian hamsters despite elevated estradiol levels. Horm Behav 41: 316-320.

Kandel DB, Chen K (2000). Extent of smoking and nicotine dependence in the United States: 1991-1993. Nicotine Tob Res 2: 263-274.

Kenny PJ, Cheeta S, File SE (2000a). Anxiogenic effects of nicotine in the dorsal hippocampus are mediated by 5 -HT1A and not by muscarinic M1 receptors. Neuropharmacology 39: 300-307.

Kenny PJ, File SE, Neal MJ (2000b). Evidence for a complex influence of nicotinic acetylcholine receptors on hippocampal serotonin release. J Neurochem 75: 2409-2414.

Klein Marcondes F, Miguel KJ, Melo LL, Spadari-Bratfisch RC (2001). Estrous cycle influences the response of female rats in the elevated plus-maze test. Physiol Behav 74: 435-440.

Laviola G, Adriani W, Terranova ML, Gerra G (1999). Psychobiological risk factors for vulnerability to psychostimulants in 
human adolescents and animal models. Neurosci Biobehav Rev 23: 993-1010.

Nides MA, Rakos RF, Gonzales D, Murray RP, Tashkin DP, Bjornson-Benson WM et al (1995). Predictors of initial smoking cessation and relapse through the first 2 years of the Lung Health Study. J Consult Clin Psychol 63: 60-69.

Ouagazzal AM, Kenny PJ, File SE (1999). Modulation of behaviours on trials 1 and 2 in the elevated plus-maze test of anxiety after systemic and hippocampal administration of nicotine. Psychopharmacology (Berl) 144: 34-60.

Pellow S, Chopin P, File SE, Briley M (1985). Validation of open: closed arm entries in an elevated plus-maze as a measure of anxiety in the rat. J Neurosci Methods 14: 149-167.

Pellow S, File SE (1986). Anxiolytic and anxiogenic drug effects on exploratory activity in an elevated plus-maze: a novel test of anxiety in the rat. Pharmacol Biochem Behav 24: 525-529.

Perkins KA, Donny E, Caggiula R (1999). Sex differences in nicotine effects and self administration: review of human and animal evidence. Nicotine Tob Res 1: 301-315.

Perkins KA, Epstein LH, Sexton JE, Solberg-Kassel R, Stiller RL, Jacob RG (1992). Effects of nicotine on hunger and eating in male and female smokers. Psychopharmacology (Berl) 106: 53-59.

Picciotto MR, Brunzell DH, Caldarone BJ (2002). Effects of nicotine and nicotinic receptors on anxiety and depression. Neuroreport 13: 1097-1106.

Pomerleau CS, Ehrlich E, Tate JC, Marks JL, Flessland KA, Pomerleau OF (1993). The female weight-control smoker: a profile. J Subst Abuse 5: 391-400.
Spear LP, Brake SC (1983). Periadolescence: age-dependent behavior and psychopharmacological responsivity in rats. Dev Psychobiol 16: 83-109.

Stanton WR (1995). DSM-III-R tobacco dependence and quitting during late adolescence. Addict Behav 20: 595-603.

Steenbergen HL, Farabollini F, Heinsbroek RP, Van de Poll NE (1991). Sex-dependent effects of aversive stimulation on holeboard and elevated plus-maze behavior. Behav Brain Res 43: 159-165.

Taioli E, Wynder EL (1991). Effect of the age at which smoking begins on frequency of smoking in adulthood. N Engl J Med 325: 968-969.

Tropp J, Markus EJ (2001). Effects of mild food deprivation on the estrous cycle of rats. Physiol Behav 73: 553-559.

Vale AL, Green S (1996). Effects of chlordiazepoxide, nicotine and -amphetamine in the rat potentiated startle model of anxiety. Behav Pharmacol 7: 138-143.

$\mathrm{Xu}$ Z, Seidler FJ, Cousins MM, Slikker W, Slotkin TA (2002). Adolescent nicotine alters serotinin receptors and cell signaling mediated through adenylyl cyclase. Brain Res 951: 280-292.

Xu Z, Seidler FJ, Slikker W, Slotkin TA (2001). Fetal and adolescent nicotine administration: effects on CNS serotonergic systems. Brain Res 914: 166-178.

Yoshihara T, Honma S, Katsuno Y, Honma K (1996). Dissociation of paraventricular NPY release and plasma corticosterone levels in rats under food deprivation. Am J Physiol 271: E239E245. 